\title{
Non-crop host plants of Tetranychus spider mites (Acari: Tetranychidae) in the field in Okinawa, Japan: Determination of possible sources of pest species and inference on the cause of peculiar mite fauna on crops
}

\author{
Suguru Ohno, ${ }^{1, *}$ Akiko Miyagi, ${ }^{2}$ Tomoko Ganaha-Kikumura, ${ }^{1}$ Tetsuo Gotoh, ${ }^{3}$ \\ Keisuke KiJima, ${ }^{1}$ Tsuyoshi OoIshI, ${ }^{2}$ Chie Moromizato, ${ }^{4}$ Dai HaRAguchI, ${ }^{5}$ \\ Kaname YoNAMINE ${ }^{6}$ and Takumi UeZATo ${ }^{5}$ \\ ${ }^{1}$ Okinawa Prefectural Agricultural Research Center; Itoman, Okinawa 901-0336, Japan \\ ${ }^{2}$ Miyakojima Branch, Okinawa Prefectural Agricultural Research Center; Miyakojima, Okinawa 906-0012, Japan \\ ${ }^{3}$ Laboratory of Applied Entomology and Zoology, Faculty of Agriculture, Ibaraki University; Ami, Ibaraki 300-0393, Japan \\ ${ }^{4}$ Okinawa Prefectural Nanbu Agricultural Development Center; Haebaru, Okinawa 904-2155, Japan \\ ${ }^{5}$ Okinawa Prefectural Plant Protection Center; Naha, Okinawa 902-0072, Japan \\ ${ }^{6}$ Ishigaki Branch, Okinawa Prefectural Agricultural Research Center; Ishigaki, Okinawa 907-0003, Japan
}

(Received 12 January 2010; Accepted 14 May 2010)

\begin{abstract}
The species composition of spider mites on crops in Okinawa is peculiar in that Tetranychus okinawanus and T. piercei are dominant on most islands, whereas T. urticae (green form) and T. kanzawai are not. To determine the source plants of Tetranychus species infesting crops, as well as to contribute to our understanding of the cause of this peculiar mite fauna, we collected Tetranychus mites on non-crop plants throughout Okinawa (more than 450 sites on 15 islands) and identified them. Except in the case of T. parakanzawai, the species frequently found on crops tended to occur frequently on non-crop plants, suggesting that the peculiar species composition on crops reflects that also on non-crop plants. T. parakanzawai has been rarely found on crops but frequently found on particular non-crop plants, possibly due to the narrower host range of this species. The type of host plants varied among mite species; for example, T. okinawanus was frequently found on indigenous plants inhabiting the seashore and invasive weeds, T. piercei and T. parakanzawai on inland indigenous plants, T. urticae (green form) on invasive weeds, and T. neocaledonicus on introduced trees. These results are of great significance when considering vegetation control as a tactic for the integrated management of spider mites.
\end{abstract}

Key words: Beach; host range; invasive species; Tetranychus ludeni; T. pueraricola

\section{INTRODUCTION}

The spider mite genus Tetranychus (Acari: Tetranychidae) contains many species injurious to agricultural crops, among which T. urticae Koch (green form and red form) and T. kanzawai Kishida have been considered the major pest species in East Asia, including Taiwan and the main islands of Japan (e.g., Ehara and Shinkaji, 1996; Ho, 2000). T. truncatus Ehara is regarded as another major pest in Taiwan (Ho, 2000). However, we recently clarified that this is not the case on vegetable crops in Okinawa, which is composed of many small is- lands lying between Taiwan and the main islands of Japan (Ohno et al., 2009). Eight Tetranychus species were found infesting crops but $T$. urticae (red form) and T. truncatus were not found in Okinawa. Among the eight species, T. okinawanus Ehara and T. piercei McGregor were the most dominant and second most dominant species, respectively, even though they have not been considered major pests in Taiwan or on the main islands of Japan (Ehara and Shinkaji, 1996; Ho, 2000; Takafuji and Ohashi, 2004). In contrast, T. urticae (green form) and T. kanzawai were not necessarily common in Okinawa. They were comparable in

* To whom correspondence should be addressed at: E-mail: oonosugr@pref.okinawa.lg.jp DOI: 10.1303/aez.2010.465 
their frequency of occurrence to $T$. piercei in the northern part of Okinawa (the Okinawa Islands), while scarce in the southern part (the Sakishima Islands). Instead, T. neocaledonicus André, which occurs on Taiwan but is not common on crops there (Ho, 2000; Takafuji and Ohashi, 2004), was the third-most dominant species in the Sakishima Islands, while this species was the fifth most dominant in the Okinawa Islands. As other minor pest species, T. ludeni Zacher, T. parakanzawai Ehara and T. pueraricola Ehara \& Gotoh occurred on crops at lower frequencies in Okinawa. This peculiar distribution of Tetranychus spider mites on crops in Okinawa needs to be explained.

Elucidation of non-crop plants utilized by pest spider mites is of great significance to integrative management in terms of the determination of possible source plants/environments (e.g., Morishita, 1992; Morishita and Takafuji, 1999). Further, knowledge of the distribution of Tetranychus spp. on non-crop hosts may aid our understanding of the peculiar fauna of this genus on crops in Okinawa; however, only a few preliminary surveys have reported non-crop hosts of Tetranychus in Okinawa (Ehara, 1966; Gotoh et al., 1996; Takafuji and Ohashi, 2004). To further understand the spider mite fauna of Okinawa, we extensively collected Tetranychus mites infesting non-crop plants throughout the area and identified them to the species level. Based on the data, we discuss the possible source of each of the eight Tetranychus species as well as the possible cause of the peculiar fauna of Tetranychus in Okinawa.

\section{MATERIALS AND METHODS}

From June 2007 to November 2009, leaves of weeds and trees with spider mite damage recognizable by the naked eye were collected from more than 450 sites on 15 inhabited islands (Fig. 1): Okinawa Island, Iheya Island, Izena Island, Ie Island, Minna Island, Kume Island and Kudaka Island (belonging to the Okinawa Islands); Miyako Island, Irabu Island, Tarama Island, Ishigaki Island, Taketomi Island, Kuro Island, Iriomote Island and Yonaguni Island (belonging to the Sakishima Islands). Collections were made at least three times in different seasons for the majority of the islands, while Izena Island, Minna Island, Kudaka Island, Tarama Island, Taketomi Island and Kuro Island were only surveyed once. If samples were collected from a small island connected to one of the above islands by a bridge (e.g., Yagaji Island and Miyagi Island connected to Okinawa Island, and Ikema Island and Kurima Island connected to Miyako Island), the data were included among those of the larger island. The majority of plant samples were collected in cultivated areas and surrounding areas, such as forest edges, settlements, roadsides and vacant lots, while indigenous weeds and trees inhabiting the seashore (mostly sandy beach) were additionally examined. Any vegetable or ornamental plants infested by spider mites were also collected to examine whether the same mite species occurred on

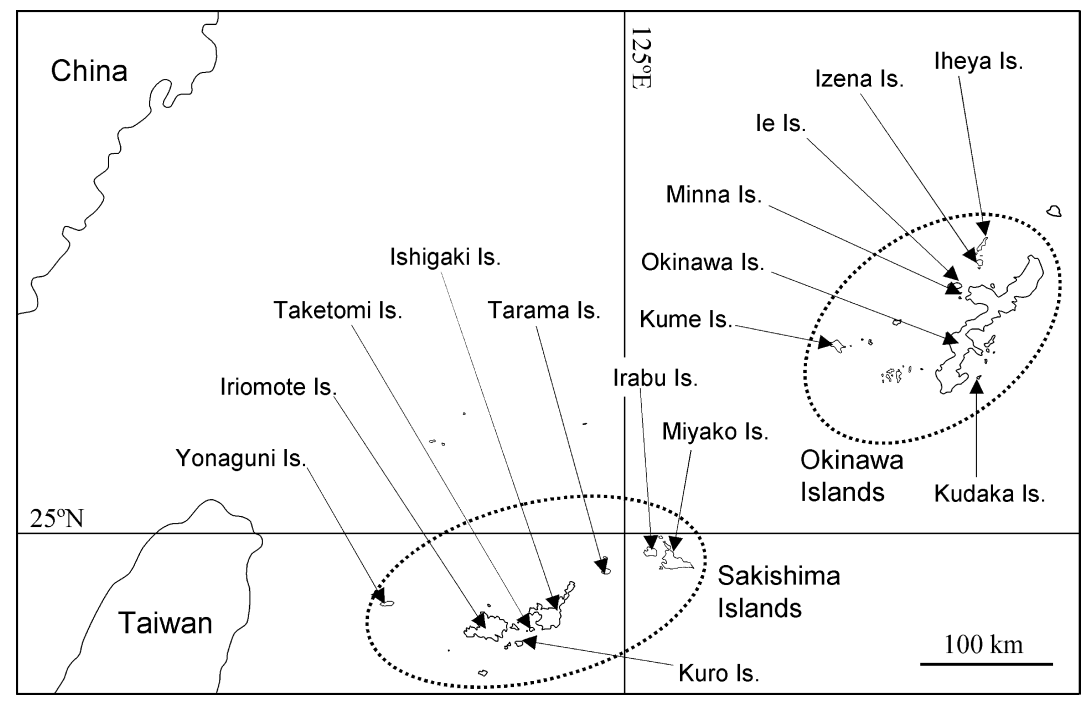

Fig. 1. Location of the 15 islands of Okinawa surveyed in the present study. Is, Island. 
both crop and non-crop plants at the same site and to present additional host records to Ohno et al. (2009).

Mites were identified first as a member of the genus Tetranychus based on the key provided by Ehara and Gotoh (2007), and then to the species level based on observations (and if necessary, measurements) of male aedeagi. If the mites in a sample did not include adult males, they were allowed to reproduce on leaf discs of Aino mulberry (Morus australis Poir.), kidney bean (Phaseolus vulgaris L.), or the collected plant, and were identified when male offspring were obtained. When the co-occurrence of different species in one sample was suspected based on observations of the body coloration of adults (see description by Ehara and Gotoh, 2007), the male aedeagi of multiple (up to 20) individuals were checked for confirmation. Voucher specimens were preserved separately by S. Ohno of Okinawa Prefectural Agricultural Research Center (OPARC), A. Miyagi of Miyakojima Branch of OPARC, and T. Gotoh of Ibaraki University, as slide-mounted specimens using Hoyer's medium. Raw collection and species identification data used in the present study are available from the first author.

Our extensive survey produced much new information on the geographic distribution and host plants of spider mite species. Since data on Tetranychus takafujii Ehara \& Ohashi $(=T$. evansi Baker and Pritchard; see Gotoh et al., 2009) and $T$. phaselus Ehara, which have been found only on non-crop plants in Okinawa, are presented elsewhere (Ikeshima et al., 2009; Ohno et al., 2010), the present study treated the data for Tetranychus species other than these two species. New distribution records of mite species were determined by referring to Ohno et al. (2009) and references therein. New host records were determined by referring to the worldwide host list provided by Migeon and Dorkeld (2006).

We regarded the number of collection sites for each mite species as an indicator of the frequency of occurrence of the species, as in Ohno et al. (2009). Non-crop plants collected were classified into the following seven categories: (I) indigenous weeds inhabiting the seashore, (II) indigenous trees inhabiting the seashore, (III) indigenous weeds inhabiting non-seashore environments, (IV) indigenous trees inhabiting non-seashore environments,
(V) invasive weeds including those considered archaeophytes, (VI) non-native herbal plants planted for ornamental purposes and/or as green manure, and (VII) non-native introduced trees. In the present study, a plant species which was not mentioned as an introduced species in several colored guides and checklists (e.g., Osada, 1976; Hatusima and Amano, 1994; Yonekura and Kajita, 2006) was considered to be indigenous to Okinawa. Data on the frequency of occurrence of mite species were summarized within each of the plant categories and compared among categories. Data for plants whose category was unclear were excluded from the comparison.

\section{RESULTS}

A total of 579 samples were taken, of which 553 from 431 sites were identified to the species level. The remaining samples were not identified due to a failure either to obtain male offspring or in the preparation of slide-mounted specimens. All eight Tetranychus species known to infest crops in Okinawa were found, but not $T$. truncatus and $T$. urticae (red form). The frequencies of occurrence of the eight Tetranychus species on 15 islands are summarized in Table 1. T. okinawanus was found on all islands examined, with a higher frequency than other congeners on a majority of islands. $T$. piercei occurred second most frequently in Okinawa, and in a few islands of the Sakishima Islands it was more dominant than T. okinawanus. T. kanzawai and T. urticae (green form) were as common as $T$. piercei in the Okinawa Islands, while they were relatively scarce in the Sakishima Islands. $T$. neocaledonicus was found at a similar frequency to T. kanzawai and T. urticae (green form) in the Okinawa Islands, but was more frequent than the two species in the Sakishima Islands. T. ludeni was newly found in the western part of the Sakishima Islands, resulting in a broad distribution in Okinawa, but was not common throughout the area. $T$. pueraricola was recorded only on two islands of the Okinawa Islands but not on the Sakishima Islands. T. parakanzawai was found to commonly occur throughout Okinawa, being the second and third most frequent species in the Okinawa Islands and the Sakishima Islands, respectively.

Host records in the present study are listed in the Appendix. T. okinawanus had the broadest host 
Table 1. Geographic distribution and frequency of occurrence of eight Tetranychus spp.

\begin{tabular}{|c|c|c|c|c|c|c|c|c|c|}
\hline \multirow{2}{*}{ Locality } & \multirow{2}{*}{$\begin{array}{c}\text { No. } \\
\text { sampling } \\
\text { sites }^{\mathrm{a}}\end{array}$} & \multicolumn{8}{|c|}{ No. sites at which each mite species was found ${ }^{b}$} \\
\hline & & T.o. & T.pi. & $T . k$ & T.u.g. & T.n. & T.l. & T.pu. & T.pa. \\
\hline \multicolumn{10}{|l|}{ Okinawa Islands } \\
\hline Okinawa Island & 180 & 72 & 23 & 21 & 16 & 23 & 2 & 13 & 33 \\
\hline Iheya Island & 26 & 16 & $1^{*}$ & $1^{*}$ & & 3 & 5 & & $3^{*}$ \\
\hline Izena Island & 1 & $1 *$ & & & & & & & \\
\hline Ie Island & 6 & $2 *$ & $1 *$ & $2 *$ & $2 *$ & & & & $1 *$ \\
\hline Minna Island & 1 & $1 *$ & & & & & & & \\
\hline Kume Island & 32 & 16 & 5 & 1 & 6 & $3 *$ & & $1 *$ & $4^{*}$ \\
\hline Kudaka Island & 1 & $1 *$ & & & & & & & \\
\hline Total & 247 & 106 & 30 & 25 & 24 & 29 & 7 & 14 & 41 \\
\hline \multicolumn{10}{|l|}{ Sakishima Islands } \\
\hline Miyako Island & 70 & 25 & 32 & 2 & 5 & $4 *$ & 1 & & $7 *$ \\
\hline Irabu Island & 20 & 10 & 7 & & & & 1 & & $5^{*}$ \\
\hline Tarama Island & 6 & $4^{*}$ & & & & & $3^{*}$ & & \\
\hline Ishigaki Island & 45 & 23 & 11 & 1 & & 6 & & & $9 *$ \\
\hline Taketomi Island & 4 & $3 *$ & & & & & & & $1 *$ \\
\hline Kuro Island & 6 & $6^{*}$ & $1 *$ & & & & $1 *$ & & \\
\hline Iriomote Island & 18 & 3 & 4 & & & & $1 *$ & & $10^{*}$ \\
\hline Yonaguni Island & 14 & 6 & $10^{*}$ & & & & & & \\
\hline Total & 183 & 80 & 65 & 3 & 5 & 10 & 7 & & 32 \\
\hline
\end{tabular}

${ }^{\text {a }}$ Data from different plant species were pooled within each island. Collections from different plant species at the same site were considered to be a single sampling. When multiple samplings were made at the same site on different dates, they were treated as a single sampling.

${ }^{\mathrm{b}}$ Species abbreviations are as follows: T.o., T. okinawanus; T.pi., T. piercei; T.k., T. kanzawai; T.u.g., T. urticae (green form); T.n., T. neocaledonicus; T.l., T. ludeni; T.pu., T. pueraricola; T.pa., T. parakanzawai. The sum of the numbers of sites across different species usually exceeds the total number of sampling sites due to the co-occurrence of multiple species at single sites. A newly recorded distribution at the island level is denoted with an asterisk.

range in the field; this species was found on at least 51 non-crop plant species from 23 families, most of which were newly recorded host plants. The host range of $T$. pierce $i$ was the second broadest with at least 34 species from 15 families, again most of them new hosts. The numbers of recorded host species (families) of T. kanzawai, T. urticae (green form), T. neocaledonicus and T. ludeni were similar, being at least 13 (10), 16 (12), 20 (15) and 13 (10), respectively. T. parakanzawai showed a narrower host range than the above six species, occurring on at least 12 species from seven families, among which all the identified plants were newly recorded hosts. T. pueraricola was found on only one fabaceous species, the Taiwan kudzu vine Pueraria montana.

Table 2 shows the frequency of occurrence of each mite species summarized by the type of host plant. On indigenous plants inhabiting the seashore (categories I and II), T. okinawanus was clearly dominant and other species were scarce. Species composition on indigenous plants inhabiting nonseashore environments (categories III and IV) showed different characteristics: T. piercei and $T$. parakanzawai were dominant, followed by other species. The relative frequency of the occurrence of $T$. piercei and T. parakanzawai varied between weeds and trees for both seashore and nonseashore indigenous plants; the former species occurred frequently on weeds, while the latter species were found rarely on weeds but frequently on trees. The dominance of $T$. okinawanus was also observed on invasive weeds (category V), while the second most dominant species in this category was T. urticae (green form). The characteristics of species composition on ornamental and green-manure herbal plants (category VI) were similar to those of invasive weeds but were unclear due to their smaller sample sizes. On introduced trees (category VII), T. neocaledonicus was clearly dominant.

Table 3 indicates the results of species identifica- 
Table 2. Frequency of occurrence of eight Tetranychus spp. in relation to the type of host plants

\begin{tabular}{|c|c|c|c|c|c|c|c|c|c|c|}
\hline \multirow{2}{*}{$\begin{array}{c}\text { Type of } \\
\text { plant }\end{array}$} & \multirow{2}{*}{ Category $^{a}$} & \multirow{2}{*}{$\begin{array}{c}\text { No. } \\
\text { sampling } \\
\text { sites }^{\mathrm{b}}\end{array}$} & \multicolumn{8}{|c|}{ No. sites at which each mite species was found ${ }^{c}$} \\
\hline & & & T.o. & T.pi. & $T . k$. & T.u.g. & T.n. & T.l. & T.pu. & T.pa. \\
\hline \multirow{4}{*}{ Indigenous } & I & 61 & 56 & 8 & & & & 3 & & 1 \\
\hline & II & 27 & 20 & & & & & & & 8 \\
\hline & III & 69 & 19 & 29 & 3 & 2 & 4 & & 14 & 3 \\
\hline & IV & 107 & 14 & 25 & 11 & 1 & 6 & 1 & & 61 \\
\hline \multirow[t]{3}{*}{ Non-indigenous } & $\mathrm{V}$ & 109 & 66 & 18 & 3 & 22 & 4 & 5 & & 2 \\
\hline & VI & 19 & 11 & 4 & 1 & 2 & 1 & 1 & & \\
\hline & VII & 53 & 11 & 11 & 8 & 1 & 26 & & & \\
\hline
\end{tabular}

${ }^{a}$ I, weeds inhabiting the seashore; II, trees inhabiting the seashore; III, weeds inhabiting non-seashore environments; IV, trees inhabiting non-seashore environments; V, invasive weeds (including those regarded as archaeophytes); VI, herbal plants grown for ornamental purposes and/or as green manure; VII, introduced trees. See Appendix for species composition of the plants in each category.

${ }^{\mathrm{b}}$ Collections from different plant species belonging to the same category at the same site were treated as a single sampling.

${ }^{c}$ Species abbreviations are the same as in Table 1. The sum of the numbers of sites across different species exceeds the total number of sampling sites due to the co-occurrence of multiple species at single sites.

Table 3. Results of mite species identification when crop and non-crop plants were simultaneously collected at the same location

\begin{tabular}{|c|c|c|c|}
\hline Island & Collection date & Crop plant (mite species ${ }^{\mathrm{a}}$ ) & Non-crop plant (mite species ${ }^{\mathrm{a}}$ ) \\
\hline \multirow[t]{5}{*}{ Okinawa } & 19 Aug. 2008 & Water spinach (T.o.) & Solanum americanum (T.o.) \\
\hline & 9 Dec. 2008 & Melon (T.n.) & $\begin{array}{l}\text { Mallotus japonicus (T.pa.); Morus australis (T.pi.); } \\
\text { Tabebuia chrysotricha (T.n.) }\end{array}$ \\
\hline & 26 Dec. 2008 & $\begin{array}{l}\text { Egyptian bean and water spinach (both T.o.); } \\
\text { taro (T.pi.); winged bean (T.k. and T.pi.) }\end{array}$ & $\begin{array}{l}\text { Amaranthus sp. (T.o.); Morus australis (T.k., T.o. and } \\
\text { T.pi.) }\end{array}$ \\
\hline & 5 Feb. 2009 & Sweet potato (T.n.) & Hibiscus rosa-sinensis and Youngia japonica (both T.n.) \\
\hline & 23 Apr. 2009 & Bell pepper (T.u.g.) & Solanum americanum (T.u.g.) \\
\hline Kume & 12 May 2009 & Carrot (T.o.) & Amaranthus sp. and Solanum americanum (both T.o.) \\
\hline \multirow[t]{5}{*}{ Miyako } & 20 May 2008 & Okra (T.pi.) & Oxalis debilis (T.pi.) \\
\hline & 18 Mar. 2009 & Kidney bean (T.pi.) & Amaranthus sp. and Oxalis debilis (both T.pi.) \\
\hline & 30 Mar. 2009 & Wax gourd (T.u.g.) & Oxalis debilis (T.u.g.) \\
\hline & 7 Apr. 2009 & Wax gourd (T.o.) & $\begin{array}{l}\text { Amaranthus sp., Medicago lupulina, Setaria sp. and } \\
\text { Solanum americanum (all T.o.) }\end{array}$ \\
\hline & 30 Jul. 2009 & Maize and melon (both T.o.) & Ipomoea biflora (T.o. and T.pi.) \\
\hline Irabu & 4 May 2008 & Cucumber (T.o.) & $\begin{array}{l}\text { Diplocyclos palmatus and Solanum americanum } \\
\text { (both T.o.) }\end{array}$ \\
\hline Tarama & 16 Mar. 2009 & Eggplant (T.o.); bell pepper (T.l.) & Amaranthus sp. and Solanum americanum (both T.o.) \\
\hline \multirow[t]{3}{*}{ Ishigaki } & 8 Nov. 2007 & Crepidiastrum lanceolatum (T.o.) & Pueraria montana (T.pi.) \\
\hline & 13 Jun. 2008 & Tomato (T.o.) & Amaranthus sp. (T.o.) \\
\hline & 22 Dec. 2008 & Okra (T.o.) & Acalypha australis and Bidens pilosa (both T.o.) \\
\hline Iriomote & 11 Jun. 2008 & Sponge gourd (T.pi.) & Melanolepis multiglandulosa (T.pa.) \\
\hline
\end{tabular}

\footnotetext{
${ }^{\text {a }}$ Species abbreviations are the same as in Table 1. Data on crop plants from 2007 to 2008 were also used by Ohno et al. (2009).
}

tion when the mites were simultaneously collected on both crop and non-crop plants at single sites. In $15(88 \%)$ out of the 17 cases, at least one mite species was shared between crop and non-crop plants.

\section{DISCUSSION}

The present study extensively examined noncrop hosts of Tetranychus species in Okinawa and determined major non-crop host plants as possible sources for the majority of the eight species found. 
These results are of great significance when considering vegetation control as a tactic for the integrated management of pest spider mites in Okinawa. T. truncatus and T. urticae (red form), which have not been found on crops in Okinawa, were not found on non-crop plants either, suggesting that they do not seem to occur in Okinawa. Overall, the mite species which occurred frequently on crops tended to occur frequently on non-crop plants. Dominant species on crops in the Sakishima Islands ( $T$. okinawanus, $T$. piercei and $T$. neocaledonicus) and the Okinawa Islands [these three species plus T. kanzawai and T. urticae (green form)] (Ohno et al., 2009) were also dominant on non-crop plants in the respective areas (Table 1). This finding provides an explanation for the peculiar Tetranychus fauna on crops in Okinawa: it reflects the abundance of each species on non-crop plants in the field. This idea is also supported by the fact that the same mite species were found on both crop and non-crop plants occurring at the same location in most cases (Table 3) which suggests the movement of mites from non-crop to crop plants. However, T. parakanzawai was a clear exception. Although this species was found only once on crops despite more than 200 samplings (Ohno et al., 2009), the present results showed that the species commonly occurs throughout Okinawa (Table 1).

We further clarified that mite species composition varied markedly among different types of noncrop plants (Table 2). This result allows us to further discuss the source and habitat of each mite species. For example, T. okinawanus was dominant on indigenous plants inhabiting the seashore, mainly the perennial weeds Vigna marina and Ipomoea pes-caprae, and the tree Scaevola taccada (see Appendix), all of which are common on sandy beaches in Okinawa. This result suggests not only that these plants are major sources of $T$. okinawanus, but also the possibility that one of the natural habitats of this mite is the seashore; therefore, cultivation fields located near the sea may be exposed to a higher risk of invasion by $T$. okinawanus. This interpretation matches the fact that T. okinawanus is dominant in Okinawa but not on neighboring larger islands, such as Taiwan. Since a smaller island has a longer coastline relative to its area, the chance of incursion of the species from the seashore to inland would be higher on smaller islands. At present, however, it is unclear whether T. okinawanus is also abundant on seashores in Taiwan and other Asian regions, which is of great interest. Other major hosts of T. okinawanus were invasive annual herbs, such as Amaranthus spp. and Solanum americanum (see Appendix). Some papers have regarded T. okinawanus as an invasive species which uses invasive weeds as major hosts (e.g., Ohashi et al., 2003; Takafuji and Ohashi, 2004).

On crop plants in Okinawa, T. piercei was one of the most common spider mite species, while $T$. parakanzawai was rarely found (Ohno et al., 2009). We showed that both species were similarly common on non-crop indigenous plants inhabiting nonseashore environments. Interestingly, $T$. piercei was found on both weed and tree species, whereas the occurrence of $T$. parakanzawai was extremely biased toward tree species (Table 2), suggesting species difference in the preference on plant species and/or habits. The former species was collected from many plant species, among which the perennial weeds Puraria montata and Ipomoea indica, and the trees Morus australis and Melanolepis multiglandulosa, were considered major source hosts (see Appendix). In contrast, more than $80 \%$ of $T$. parakanzawai samples were collected from the trees, Mallotus japonicus, Melanolepis multiglandulosa and Clerodendrum trichotomum (see Appendix). The supposed narrow host range of $T$. parakanzawai in the field compared to other major species is possibly one of the causes of the scarcity of this species on crops.

In most cases, $T$. urticae (green form) was found on invasive weeds, such as Solanum americanum and Oxalis debilis (see Appendix), showing the importance of this kind of plant as a source of the pest. This result matches the view that this species is non-native to Okinawa, and suggests that populations of this species are mainly maintained on introduced plants in artificially developed areas. $T$. urticae (green form) is considered a worldwide invasive species originating from the Mediterranean region and thus non-native to Japan (Navajas et al., 1998; Hinomoto et al., 2001). The reason why this invasive species has not expanded its range to indigenous plants in Okinawa is of interest but unclear at present. Irrespective of their similar distribution pattern in Okinawa, T. kanzawai and T. urticae (green form) somewhat varied in the host 
usage pattern; the former species was found on both indigenous and non-indigenous plants at a similar frequency (Table 2). Among the recorded host plants of T. kanzawai, Morus australis was most frequently infested (see Appendix), suggesting that this plant is one of the most important source of this pest in Okinawa.

T. neocaledonicus had a unique host usage pattern. It was the species most frequently found on introduced trees, such as Bauhinia spp. and Jatropha integerrima (see Appendix), strongly suggesting that such trees are sources of this mite. Considering that most of the introduced trees examined were of tropical origin, T. neocaledonicus might have been introduced from tropical regions together with the trees. One of the minor species on crops, T. ludeni, was also less frequently found on non-crop plants with no clear characteristics in its host usage pattern. The scarcity of this species irrespective of its broad distribution and host ranges needs to be explained. Another minor species, T. pueraricola, showed a distinct pattern. It was found only on an indigenous perennial weed, Pueraria montana, in the Okinawa Islands. This suggests the strong host preference of $T$. pueraricola for the plant despite its potential to use a wide range of plant taxa as hosts (Gotoh et al., 2004). The narrow host range of $T$. pueraricola in the field is probably a cause of the rarity of this species on crops.

In conclusion, we have clarified a peculiar fauna of Tetranychus spider mites on both crop and noncrop plants in Okinawa (Ohno et al., 2009; present study), providing fundamental information on their integrated management in that area. One of the most marked peculiarities is that two serious pest species, T. urticae (green form) and T. kanzawai, are scarce or even not found in the southern part of Okinawa (Sakishima Islands) even though these species are common in adjacent areas (i.e., Taiwan, the Okinawa Islands and the main islands of Japan). There may be some abiotic or biotic factors (e.g., climatic condition, vegetation or specialist predators) specific to the Sakishima Islands that hamper population growth and range expansion by these species. Determination of such factors is important in that it is not only of biogeographical interest but also suggestive for controls of the two species in areas other than the Sakishima Islands.

\section{ACKNOWLEGMENTS}

We thank the following individuals who provided plant samples infested with mites and/or helped with the sampling of mites: Tsunaki Ando, Milton Antrim, Kazuyasu Futagami, Takaya Gibo, Kayoko Gibu, Junko Inoue, Kenji Isa, Kazuhiko Iyama, Yoshie Kakazu, Moriyoshi Kaneshima, Tomoko Kato, Futoshi Kawamura, Shinji Kawano, Hirosato Kodama, Tsuguo Kohama, Takashi Matsuyama, Naomi Maekado, Taku Motomura, Chihiro Miyazato, Ayako Ooishi, Yasutsune Sadoyama, Keiko Shiromoto, Hiroaki Sunagawa, Naoki Taniai, Kazuhiko Tarora, Haruki Tatsuta, Nami Uechi, Shigenori Ueda, Rie Ukuda, Seiei Yamauchi, Yoshitomo Yamada, Keiji Yasuda, Kazufumi Yoza and Jun-ichi Yukawa. Thanks are also due to Yoshifumi Takaesu who kindly identified some of our plant samples.

\section{REFERENCES}

Ehara, S. (1966) The tetranychoid mites of Okinawa Island (Acarina: Prostigmata). J. Fac. Sci., Hokkaido Univ., Ser. VI, Zool. 16: 1-22.

Ehara, S. and T. Gotoh (2007) A guide to the spider mites of Japan (Acari: Tetranychidae). Plant Prot., Spec. Issue 10: 3-33 (in Japanese).

Ehara, S. and N. Shinkaji (ed.) (1996) Principles of Plant Acarology. Zenkoku Noson Kyoiku Kyokai, Tokyo. 419 pp. (in Japanese).

Gotoh, T., A. Takafuji and K. Gomi (1996) Tetranychid mites of Okinawa Island (Acari: Tetranychidae). J. Acarol. Soc. Jpn. 5: 89-97.

Gotoh, T., A. Suwa and Y. Kitashima (2004) Development and oviposition of Tetranychus pueraricola Ehara \& Gotoh (Acari: Tetranychidae) on various plants. J. Acarol. Soc. Jpn. 13: 135-140.

Gotoh, T., R. Araki, A. Boubou, A. Migeon, F. Ferragut and M. Navajas (2009) Evidence of co-specificity between Tetranychus evansi and Tetranychus takafujii (Acari: Prostigmata, Tetranychidae): Comments on taxonomic and agricultural aspects. Int. J. Acarol. 35: 485-501.

Hatusima, S. and T. Amano (1994) Flora of the Ryukyus. 2nd edition. The Biological Society of Okinawa, Nishihara. 393 pp. (in Japanese).

Hinomoto, N., Mh. Osakabe, T. Gotoh and A. Takafuji (2001) Phylogenetic analysis of green and red forms of the twospotted spider mite, Tetranychus urticae Koch (Acari: Tetranychidae), in Japan, based on mitochondrial cytochrome oxidase subunit I sequences. Appl. Entomol. Zool. 36: 459-464.

Ho, C. (2000) Spider-mite problems and control in Taiwan. Exp. Appl. Acarol. 24: 453-462.

Ikeshima, K., Y. Sakamaki, A. Miyagi, S. Ohno, T. Fukuda and K. Tsuda (2009) Occurrence of the spider mite Tetranychus takafujii Ehara \& Ohashi in Kyushu and Okinawa. Kyushu Plant Prot. Res. 55: 136-140 (in Japanese with English summary).

Migeon, A. and F. Dorkeld (2006) Spider mites Web: A comprehensive database for the Tetranychidae. http:// www.montpellier.inra.fr/CBGP/spmweb

Morishita, M. (1992) Movement of two species of tetrany- 
chid mites (Acarina: Tetranychidae) from border vegetation to watermelon fields. Jpn. J. Appl. Entomol. Zool. 36: 25-30 (in Japanese with English summary).

Morishita, M. and A. Takafuji (1999) Life cycle and interplant movement of Tetranychus kanzawai Kishida (Acari: Tetranychidae) between crop hosts and border vegetation in pea-watermelon fields. Jpn. J. Appl. Entomol. Zool. 43: 129-134 (in Japanese with English summary).

Navajas, M., J. Lagnel, J. Gutierrez and P. Boursot (1998) Species-wide homogeneity of nuclear ribosomal ITS2 sequences in the spider mite Tetranychus urticae contrasts with extensive mitochondrial COI polymorphism. Heredity 80: 742-752.

Ohashi, K., Y. Kotsubo and A. Takafuji (2003) Distribution and overwintering ecology of Tetranychus takafujii (Acari: Tetranychidae), a species found from Kinki district, Japan. J. Acarol. Soc. Jpn. 12: 107-113 (in Japanese with English summary).

Ohno, S., A. Miyagi, T. Ganaha-Kikumura, T. Gotoh, Y. Kitashima, T. Ooishi, T. Ando, K. Kijima, K. Futagami, T.
Uesato and K. Yasuda (2009) Species composition of spider mites (Acari: Tetranychidae) on vegetables in Okinawa, southwestern Japan. Appl. Entomol. Zool. 44: 628-633.

Ohno, S., A. Miyagi, T. Ganaha-Kikumura and K. Kijima (2010) Effect of several commercial pesticides on the survival of nine Tetranychus species (Acari: Tetranychidae) inhabiting Okinawa, southwestern Japan. Kyushu Plant Prot. Res. 56 (in press, in Japanese with English summary).

Osada, T. (1976) Colored Illustrations of Naturalized Plants of Japan. Hoikusha Publishing, Osaka. xvi+64 plates + 425 pp. (in Japanese).

Takafuji, A. and K. Ohashi (2004) Spider mites recently found in Japan and their distribution. Plant Prot. 58: 212-215 (in Japanese).

Yonekura, K. and T. Kajita (2006) BG plants Japanese namescientific name index (YList). http://bean.bio.chiba-u.jp/ bgplants/ylist_main.html (in Japanese). 


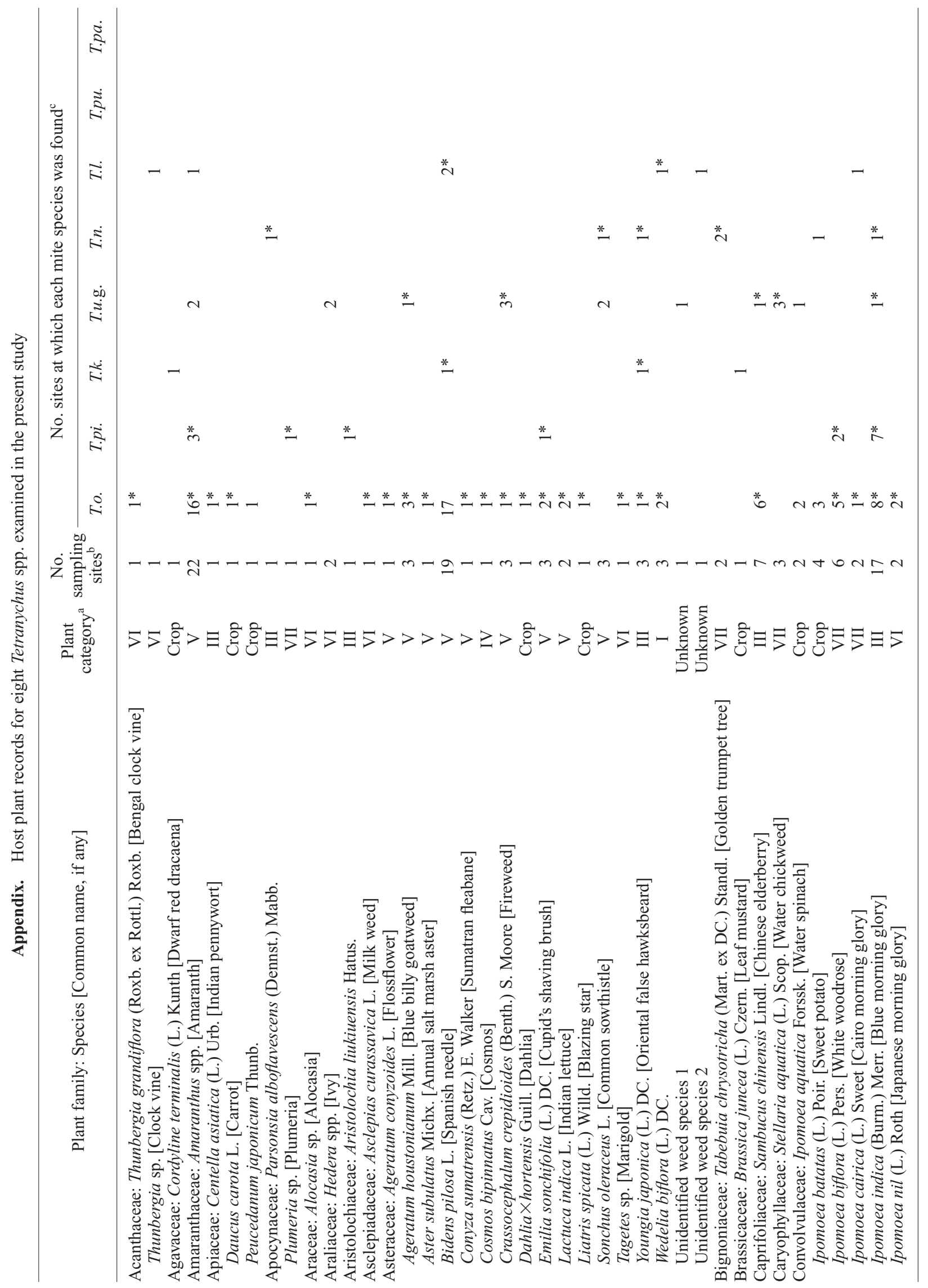




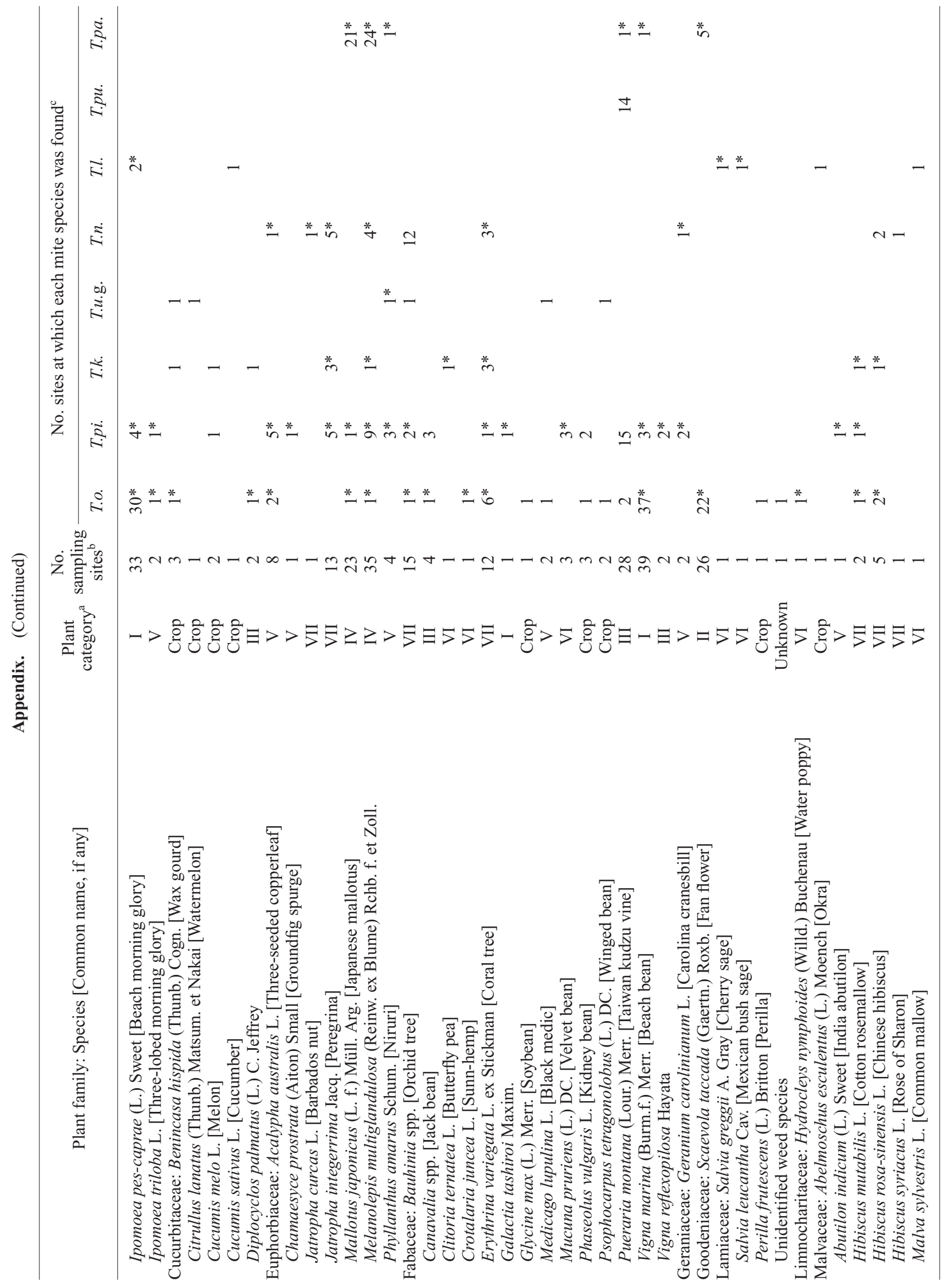


Wild Host Plants of Tetranychus spp.

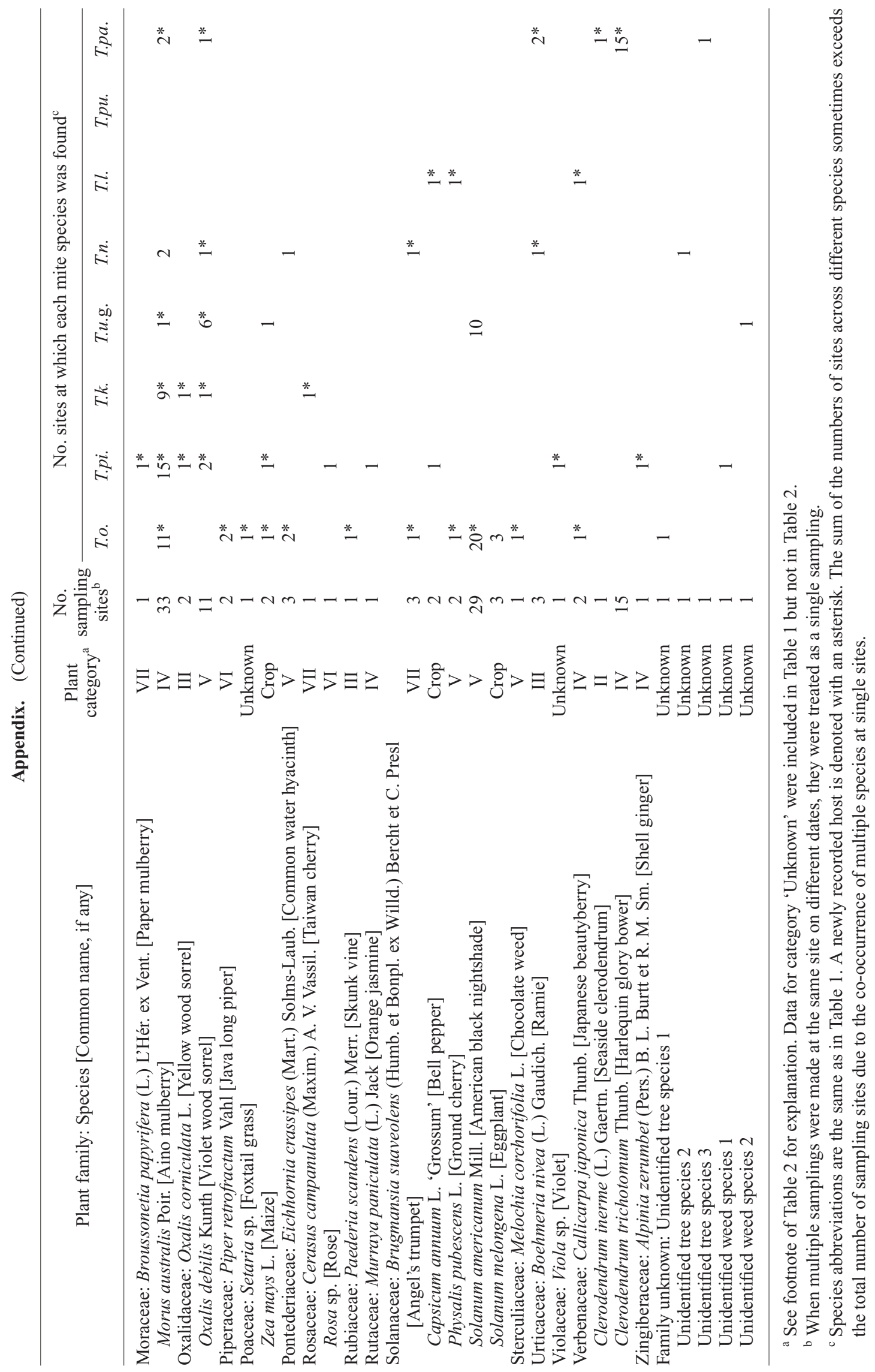

